\title{
Exploring Grade 3 Teachers' Perspectives on the Acceptability and Efficacy of MindMasters 2
}

\author{
Alexandre Santos ${ }^{1,2}$ \\ ${ }^{1}$ Children's Hospital of Eastern Ontario Research Institute, Ottawa, Ontario, Canada \\ ${ }^{2}$ School of Human Kinetics, University of Ottawa, Ottawa, Ontario, Canada \\ Correspondence: Alexandre Santos, Children's Hospital of Eastern Ontario Research Institute, Ottawa, ON., \\ K1H 5B2, Canada. Tel: 1-613-737-7600 ext. 2968. E-mail: asantos@cheo.on.ca
}

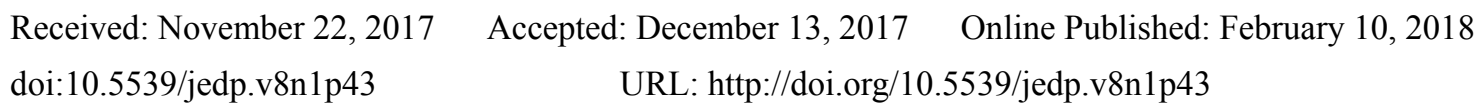

\begin{abstract}
MindMasters 2 is a curriculum resource designed to promote social and emotional skills, such as relaxation, positive thinking, and mindfulness. The purpose of this study was to assess teachers' perspectives regarding MindMasters 2's acceptability and efficacy in classrooms over a 3-month period, and obtain suggestions for future improvement. Six Grade-3 teachers took part in semi-structured interviews post-implementation, which were audio-recorded, transcribed verbatim and analyzed thematically. Nine broad themes were identified, which are discussed in detail. Overall, teachers found MindMasters 2 acceptable in a classroom setting, and observed changes in children's emotional regulation, focus in the classroom, and peer relationships. Teachers also noted children's use of the resource outside of the classroom environment. Suggestions for improvement included more training opportunities, broader variety in activities, and the addition of a parent section. According to teachers' perspectives, MindMasters 2 may be a useful resource when attempting to meet specific curriculum objectives.
\end{abstract}

Keywords: MindMasters 2, social-emotional learning, teachers' perspectives, youth

\section{Introduction}

Resilience, defined as the ability to overcome emotional, developmental, economic, and environmental challenges (Rutter, 1987), is a field of research that has expanded significantly over the last 25 years (Goldstein \& Brooks, 2012). Of particular interest is the development of resilience in the youth population. As explained by Goldstein and Brooks (2012), the number of youth facing adversity appears to be increasing, stimulating the need for sustainable interventions that promote protective factors related to resilience. Fostering a "resilient mindset" (Brooks \& Goldstein, 2001) in all youth may lead to an improvement in coping with stress and pressure, everyday challenges, adversity, and trauma, while also providing children with the tools to develop clear and realistic goals, solve problems, relate to others, and treat oneself and others with respect. Indeed, research shows that building resilience through the promotion of protective factors in children via preventative interventions may translate to a reduction in the numbers of youth with emotional, psychiatric, and behavioral problems (Goldstein \& Brooks, 2012; Hodder et al., 2017).

Protective factors related to resilience have been reported (Garmezy, 1985) and categorized (Masten, 2007). According to Masten (2007), resilience is a multifaceted concept that entails various characteristics of the child, family, community, and culture. Interestingly, some protective factors related to child characteristics (i.e. problem-solving skills, positive peer relationships, emotional and behavioral regulation, positive view of self, positive outlook on life) are also used as benchmarks for policy and practice. Of interest to this study, the Ontario Curriculum for Grades 1-8: Health and Physical Education (Ontario Ministry of Education, 2015), outlines positive living expectations and the need to promote activities that foster mental well-being, such as stress management, coping skills, adopting an optimistic attitude, and expressing emotions in a safe, productive way. Similarly, the Mental Health Commission of Canada (2012) released a national-level mental health and well-being initiative that targets many of the same protective factors found in resilience research.

Social-emotional learning (SEL) is a conceptual framework that outlines intrapersonal, interpersonal and cognitive competencies through the development of 5 core competencies: self- awareness, self-management, social-awareness, relationship skills, and responsible decision-making (Collaborative for Academic, Social \& 
Emotional Learning [CASEL], 2012). Much like the research on protective factors related to resilience, CASEL advocates for programs that target children's social and emotional development to help them build resilience and cope with adversity. SEL skills are thought to be important for improving children's emotional regulation in tough situations, as well as build positive relationships with those around them and a positive relationship with oneself. In consequence, fostering SEL skills in elementary schools may assist in decreasing the rates of mental illness and distress in the youth population, and better prepare children to positively cope with adversity in the future. One such method of fostering SEL skills is through the integration of universal, SEL-based programs into existing school agenda. Previous evaluations of school programs that focus on these SEL competencies have demonstrated decreases in school dropouts, substance abuse, unwanted teen pregnancies, and school violence (Zins, 2004), and an increase in positive social behavior, emotional stability, and academic achievement (Durlak, Weissberg, Dymnicki, Taylor, \& Schellinger, 2011; Greenberg et al., 2003). In turn, these outcomes have been linked to improved mental health in children over a prolonged duration (Bond et al., 2007; Payton et al., 2000). Regretfully, exposure to SEL opportunities has so far been minimal in Canada (Carthy Foundation \& Max Bell Foundation, 2013). Thus, interventions that focus on improving children's SEL competencies are needed to better meet the objectives set out by the provincial curriculum.

MindMasters 2 is a curriculum resource intended for children ages 4-9 that is available for free in both English and French. MindMasters 2 shares many of the same objectives as SEL programs and resilience research alike. Its primary purpose is to enhance children's coping strategies by improving their social and emotional skills through 11 activities (Children's Hospital of Eastern Ontario, 2016). MindMasters 2 activities were designed to be easy-to-use and applicable in a variety of environmental contexts, including classrooms, daycares, and homes. Each activity takes between 5-15 minutes to complete, and can be accessed from the resource's website, guidebook, or software application. Some of the activities have accompanying audio tracks and video guides, and all activities in the resource have been linked to the positive living criteria in the Ontario curriculum for health and physical education (Ontario Ministry of Education, 2015).

Activities focus on one or more of the following three social and emotional skills: relaxation and stress management, positive thinking, and mindfulness. Relaxation and stress management activities help children identify, express, and cope with feelings in a healthy manner, and learn to manage stress using different relaxation techniques. Positive thinking activities help children learn how to use positive thinking and imagery, find daily highlights and build positive relationships. Mindfulness activities help children to focus and be in the moment, and accept their thoughts and feelings without judgment. Together, these three techniques are postulated to improve a child's social and emotional functioning. Previous research has shown that an improvement in these skills may lead to better intrapersonal (Brown \& Ryan, 2003; Horn, 2008; Tang, Posner, \& Rothbart, 2014) and interpersonal competencies (Durlak et al., 2011; Harnett \& Dawe, 2012).

The integration of MindMasters 2 in schools is thought to be an essential step towards increasing children's exposure to these social and emotional skills, and promoting the adoption of a resilient mindset. In this integration process, we must keep in mind that teachers play an immense influential role in the development of youth. Indeed, a book by Stronge (2010) compiles numerous research articles that show the impact teachers can have on a child's academic and developmental growth. In light of this research, strides must be made to ensure that teachers feel adequately prepared to hold such important responsibilities. As evidenced by the provincial curriculum objectives, teachers are in dire need of resources that will facilitate the introduction and practice of these novel concepts within a classroom setting. It is therefore important to gather teachers' perspectives on MindMasters 2, to determine its acceptability in meeting curriculum objectives, and to inform future use of the resource to more adequately meet the needs of teachers.

The primary purpose of this research study was to determine whether MindMasters 2 is considered by teachers to be an acceptable and efficacious resource to use in a classroom setting. A secondary purpose was to gather teachers' opinions on how to further improve the resource. The implications from these results are then explored to guide future implementation, adding to the evidence-base for MindMasters 2 as a viable option for meeting the positive living expectations outlined by the provincial curriculum.

\section{Method}

\subsection{Participant and Procedures}

This study was conceptualized and executed in two phases. The first phase consisted of an outcomes evaluation, in which a total of 98 children from 14 different Grade- 3 classrooms found within a major Ontario school board were recruited and randomly allocated to either a control group or experimental group. Children were then assessed before and after a 3-month implementation period on their abilities to recognize, name, and manage emotions, 
demonstrate prosocial behaviors in the classroom, show empathy for others, and relax after partaking in relaxation activities. The results of the outcomes evaluation are reported in a separate manuscript.

Implementation of MindMasters 2 occurred in all experimental classrooms from the beginning of January to the end of April of 2017. Prior to implementation, the principal investigator met with all teachers one-on-one to explain the implementation process and answer questions. At this time, teachers were given a hardcopy of the resource guidebook, access to the free software application that accompanied the resource, the link to the resource's online website, and a teacher log book to keep track of when and how often each activity was used. To ensure consistency in implementation across all classrooms, teachers in the experimental group were instructed to use MindMasters 2 activities approximately three times per week, ensuring each activity was used at least three times during the 3-month period.

Student Support Partners (SSPs) were provided by the school board to assist in resource implementation. SSPs had received a 2-hour training session on implementing MindMasters 2 prior to this study, and received a 1.5-hour booster session before commencing implementation. During this booster session, SSPs were instructed to introduce each MindMasters 2 activity once to each experimental classroom, and then allow teachers to lead the activities for the remainder of the implementation period.

Once implementation of MindMasters 2 concluded, teachers in the experimental group $(n=7)$ were asked to participate in semi-structured interviews (Fylan, 2011) to elaborate on resource acceptability, efficacy, and improvement. Of the seven teachers available, six completed the interview process, as one teacher was not available due to a conflict in scheduling. Ethical approvals were granted for this study by a pediatric hospital's Research Ethics Board, a university's Research Ethics Board, and the relevant school board's Research Steering Committee.

\subsection{Interviews}

Semi-structured interviews were chosen as the main method of exploring teachers' perspectives of the resource, as it gave teachers the opportunity to share their thoughts in a personal, yet confidential manner. To ensure the research objectives were being addressed during the interviews, an interview guide was created. The interview guide was tested with a pilot interview, which was conducted with one of the study participants to ensure questions were clear, concise, and on topic (van Teijlingen \& Hundley, 2002). Following the pilot interview, a few modifications were made to the interview guide, but the answers provided by the participant still provided quality data, and so were included in the analysis. Modifications to the interview guide were peer-reviewed, and the final product was used in subsequent interviews.

Interviews were conducted within two weeks after MindMasters 2 implementation ended. Interviews were done in person by the principal investigator, in a quiet area of the participating schools. Before the interviews began, participants were asked to answer questions honestly, and were informed that they did not have to answer any questions with which they felt uncomfortable. Participants also provided verbal consent to being audio recorded during the interview. All interviews were audio recorded and anonymized. The interviews lasted from 12 to 25 minutes $(M=17.08)$ in length. Interviews were purposely kept to a short duration in accordance with ethical guidelines, to accommodate teachers' busy schedules.

\subsection{Analysis}

Thematic analysis was used to analyze the interview data (Braun \& Clarke, 2006). Audio-recorded interviews were transcribed verbatim following guidelines specified by Braun and Clarke, generating a total of 48 pages. The principal investigator read and re-read the transcripts, taking notes on initial ideas in order to develop preliminary codes in a systematic fashion. Via collation of these codes, potential themes were identified as repeated topics of discussion in multiple interview transcripts. The initial set of themes identified by the principal investigator was reviewed through peer-review briefing, and changes to the themes were made accordingly. Once themes were given clear definitions and names, NVivo 11.0 (QSR International Pty Ltd, 2015) was used to assist in the electronic coding and retrieval of interview transcripts. A total of three node levels in the coding tree were created to assist in specifying sub-themes within each existing theme. Vivid quotes from participants that portrayed the theme in question were chosen to be included in this manuscript. Quotes used in this paper have been labeled according to the participant's identification number, given at the time of the interview to maintain confidentiality.

\section{Results}

Nine broad themes were identified from the interviews: Frequency of Implementation; Timing of Implementation; Modality of Implementation; Barriers to Implementation; Observed Changes Due to Resource; Resource Likeability; Resource Transferability; Suggestions for Improvement; and Future Use of Resource. A summary of 
the key themes and sub-themes are presented next with accompanying quotes from teachers.

\subsection{Frequency of Implementation}

Most teachers interviewed stated that they tried using the resource a minimum of three days a week. However, the frequency of implementation varied due to unforeseen circumstances. Participant 4 explains:

I tried to use it [the resource] three times a week. Some days I did three days a week, some days I did one day a week. I even think I missed a week, because of snow days and things like that. I tried to do three days a week, but it varied. (Participant 4)

Frequency of implementation for each activity was also reported in teacher log books. On average, teachers introduced each activity 3.06 times $(S D=0.25)$ over 3 months. Despite some variations, 5 of the 6 teachers interviewed were able to meet the standard agreed upon: introducing each of the 11 activities three times each during the implementation period.

\subsubsection{Routine versus Sporadic Use}

The majority of teachers thought that the resource was most effective when integrated into a routine. Participant 3 explains why:

...I think for some groups, especially the one that I have, making it part of a routine, especially after a transition time, was kind of key, because they knew that this was now their calming down time. Whatever had happened at recess was now no longer. It was forgotten about, and now we can focus and do that activity... I would recommend making it part of their routine, especially after transition time, just because it's a good turning point for a lot of those students who aren't able to self- regulate. (Participant 3)

Although all teachers were using the resource as part of their classroom routine, some teachers still thought that using the resource sporadically could work in given situations. Participant 2 was one such teacher:

I think you can use it sporadically. I think it totally depends on your group. I think mine kind of thrive on the routine, and expecting it and enjoying it, whereas if I had a different group from the past where they were more needs, more anxiety, I think you can put it in sporadically when you kind of see things are elevating. Or the beginning of the day, if you see they've come in a little bit off, I think you could use it wherever you need. (Participant 2)

When asked if they thought the resource could be used sporadically, two teachers in particular did not believe that using the program in such way would yield the program's desired effects. One teacher stated, "I think that would be my big thing to teachers. You can't use it five times and expect it to change. It's got to be a slow progression." (Participant 1). Participant 5 had a similar thought:

I don't think so. With this group, even in the beginning when it wasn't the routine, it was very noisy and they weren't quite following the instructions, and it was more of a game than an actual technique they should use. Whereas now, it's very quiet. They know exactly what to do. (Participant 5)

\subsection{Timing of Implementation}

Teachers used the resource at three main times during school hours: as soon as they began the day, after recess, and at the end of the day. Most teachers used MindMasters 2 activities after recess, as one teacher shares, "They come in from that unstructured time [recess], so they're usually coming in pretty high. It was a perfect time to do the MindMasters2." (Participant 2). Another teacher used the activities at the end of the day:

For us, we transitioned at the end of the day when they were packing up and finishing at the carpet, and we kind of [used the program] to bring them down. Or when they're coming back from recess or coming back from gym and you kind of need to bring them down. (Participant 3)

\subsubsection{Transitions}

The majority of teachers used the MindMasters 2 activities during transition periods as a way of calming the children and getting them focused on the class subject. Some teachers even recommended using the program in such a way to other teachers, as participant 1 notes, "If I'm transitioning from language to math, and I feel like they're hyper, I'll do an activity just as a way to calm them down." Other teachers shared the same view:

I don't usually have them first thing in the morning, so when I would come in at 9:40, it was often then [that the activity was used]. It was kind of a transition between what they had just finished. They could be a little riled up after music, so it'd be a little kind of transition and calm down before we got into our language. (Participant 2)

It's a great transition. That's when I would recommend it, during transition time, and I really would suggest it to 
teachers, even if they just go to that website, and do some activities and get it into their routine so the kids learn it. (Participant 3)

\subsection{Modality of Implementation}

For the most part, teachers used the online website to deliver the resource to their classrooms. Reasons for doing so included the website being well organized and easy to access, as participant 3 explains, "Yeah it had it all together there [the website], so it was like a one-stop kind of shop that I could put up, and they knew to just click on it." Participant 4 also had a similar opinion:

I used the website the most. It was great. Especially with the smart board, I just put it right up there, and it was much easier for me because I had to do less right? The first time, I'm looking back at the book and I'm like 'okay what do I need to say here, or what do I need to do here?', whereas the website was really easy. You just click on it, and it talks them through it, which I found really helpful. (Participant 4)

Teachers sometimes used the guidebook hardcopy to implement the resource. However, this was not nearly as common as the website, as the guidebook can also be found online as a document. Surprisingly, none of the teachers used the software application. As one teacher explains, the technological limitations were the cause:

No, I didn't use the app. I wanted to try the app. Timewise, I couldn't, and in the portable it's tricky to get the technology out there, so we didn't really use the app. If I were to do it again, I would use the app for sure. (Participant 2)

\subsection{Challenges to Implementation}

\subsubsection{Time}

According to teachers, one of the most common challenges to implementing the resource was a lack of time. Adding to the issue was the fact that many of their classrooms lost days of school due to environmental factors (i.e. snow days), making it even harder to implement the program on a regular basis. Participant 4 explains:

Time restriction was the biggest thing I found. And I think just the fact that I'm not here every day of the week. The other teacher is here, but she wasn't doing the program, it was really just me. So those days when I'm not here and she's in the class, it didn't get done. (Participant 4)

\subsubsection{Coordinating With SSPs}

Another challenge was scheduling conflicts with the SSPs designated to help with the implementation process. Such conflicts would mean that introducing new activities would sometimes have to be introduced by the teachers who were unfamiliar with the activities, as was the case with participant 1 :

It's been tricky because she [the SSP] is here twice a week, and if she has a big upheaval somewhere else, she's not in for the week. So sometimes I had to run them on my own, and that's a challenge too. (Participant 1)

\subsubsection{Buy-in From Kids}

Some of the teachers felt that children were often not interested in doing the activities at first. This created a challenge, as these students would often influence the other children by acting out. However, as time progressed, teachers saw an improvement in participation from the more challenging students. This was well portrayed by two of the teachers:

My biggest one [challenge] is just the fact that I feel the kids that need it the most don't want to buy-in when we do it... and I don't know if it's because those are the kids that have a hard time. They're very self-aware as far as knowing their emotions, and recognizing them. They're really good at that, but I don't know if they want to acknowledge their feelings all the time. (Participant 1)

Probably four of the boys [weren't buying-in]. I don't know if they maybe felt uncomfortable, just because it's kind of something that they're not used to, and they'd make little noises or kind of fidget, try and distract themselves... they got better towards the end. Towards the end, I did see them, the last couple of times, where they would participate more. (Participant 6)

\subsection{Observed Changes Due to Resource}

\subsubsection{Classroom Climate}

When asked if they thought the program had changed the "climate" of their classroom, such as noise level and level of focus, teachers were mostly in agreement that it had. Participant 6 states, "Especially towards the end, once they got more used to doing the activities", children were able to take the activities more seriously. Participant 1 noted a change in the acceptability of the resource over time: 
There's been a slow pendulum switch to the fact that it's okay to do it, and that they're not feeling singled out. At the beginning, they'd close their eyes, but they were peeking to see if people were watching. Now, they're more comfortable, and they're not looking to see if others are watching. They don't care. (Participant 1)

However, participant 5 did not observe any changes in classroom climate which she could attribute to MindMasters 2, "There were a few examples like that where they said they were using it but I thought, did it change the whole feeling of the class? No, I don't think so."

\subsubsection{Emotional Regulation}

Many of the teachers saw an improvement over time in children's ability to understand and manage their feelings. Three quotes in particular capture their observations well:

I think they're just more in tune with their feelings and how they're feeling. I can quickly say 'oh you seem to be feeling, I don't know, frustrated. Could you go do Jelly Belly? Making reference to it, the kids will go, and I don't know whether they do it internally or not, but just knowing it, it seems to be able to tweak them to change their behavior. (Participant 1)

The first few times, they were very silly and unfocused and it took a while for them to even stay focused to it, but then as we did it, and as the program continued, it got much better, and they were calm, and it did its purpose. (Participant 4)

I feel like they're better at relaxing when they're stressed. I know a couple of my high-flier kids still do have problems with controlling their temper, I guess you would say. A lot of the other ones, whenever they're stressed, or if they had a bad dream, I feel like that's when they were most effective at being able to use it. (Participant 6)

\subsubsection{Focus}

Similar to emotional regulation, teachers saw an improvement in children's ability to focus in class after an activity, especially during transition periods. Participant 4 explains her observations:

I try to do a guided writing thing at the end of the day too, where we write on our Facebook page and do it together. That's a time where sometimes they're not always a hundred percent focused, and I'm like 'okay, you guys have to focus'. So I would often do it right before that, because they all would have to come to the carpet for that anyway. It just lent itself well, because they were coming to the carpet. So I put on MindMasters 2, and then we'd do the shared writing activity, and it did help with that. (Participant 4)

\subsubsection{Peer Relationships}

There were a few examples of when teachers observed children helping their peers during implementation. However, this was not reported often. One teacher said, "I've heard them telling each other 'you should go do this activity because you're stressed. You should go do Jelly Belly, you're super whacky right now" (Participant 1). Another teacher observed, "...especially with the yoga to start [laughter]. Some of them were very good, others had a few issues, so they would say 'oh no, try this', and show them. So they definitely would help each other" (Participant 2).

\subsection{Resource Likeability}

Overall, all teachers liked the program and found it acceptable in a classroom setting. The main reasons teachers gave were its ease of use and simplicity. Teachers also reported that students found the activities fun, and that conducting the activities did not take very long. All of these characteristics are portrayed in the following quotes:

I like that it's easy. Honestly, for a teacher with not a lot of time, it's very easy to follow; everything you need is right there and laid out for you, so it's very easy... I think the activities were simple and fun and I think that's why the kids really enjoyed it. (Participant 2)

I think it was really straightforward... it was easy for me to look at the book and to go to the links that you sent me... I've found it easy to follow, easy to use, and the kids liked the songs; they loved to sing them. (Participant 3)

The activities were short, they were usable, and the kids enjoyed them, because if they didn't enjoy them it would have been painful. I like how there was variety so we could change it up. I like how they felt afterwards. I liked how they were thinking and actually using it outside of it [the classroom]. It shows that they were effective so that was good. But it was just easy and positive. (Participant 5)

I liked that the activities the kids could actually do. They weren't complicated, they were really easy, they were quick, and they didn't take up too much time. I liked having the audio clips, so then it could play and they could just listen to the voice on the computer. (Participant 6) 


\subsection{Resource Transferability}

A prominent topic of discussion during the interviews was the relevance of MindMasters 2 outside of the classroom. Most teachers felt that the activities the kids learned in the classroom were being applied in everyday situations, including conflicts during recess, sports situations, and even when trying to sleep:

We've talked about, if you're at home and you're not able to sleep how you can use these activities and try to apply it to their everyday world, so it's not just something that they use here... We've talked about if they're an athlete and they're nervous before a hockey game, that athletes use these activities and, I think when I make it applicable to someone like a Sidney Crosby doing something like this, then all of a sudden [they were interested]. (Participant 1)

We talked about using it outside of the class, and they talked about when they feel stressed and stuff like that, and different situations, like out in the yard. And I have a lot of really competitive boys in this classroom, and recesses are usually always an issue. And gym is always an issue too. They're super competitive and they get super upset if they're not winning, so we talked about that, and using it. (Participant 4)

A few of them are using it before they go to sleep. A few of them are using it when they get angry, and actually there was one time in the office and I said 'this would be a good time to use your MindMasters' and he goes 'I'm trying! I'm trying to use my Jelly Belly!' (Participant 5)

\subsection{Suggestions for Improvement}

\subsubsection{Parental Involvement}

Teachers were able to provide various suggestions for improving MindMasters 2. One such suggestion was made by participant 1 to include a parent section that parents could use with their children at home:

Maybe even a parent section where you could take it home after you do the activity and then it goes home, and they see it. I've been trying to send things home as we've been doing them... a little activity as a follow-up that they can take home, and then show their parents, and maybe it'll prompt them to use it too. (Participant 1)

\subsubsection{Timeline}

A suggestion made by various teachers was to ensure that implementation started at the beginning of the school year. With this change, teachers felt that they would be more prepared to integrate MindMasters 2 within their daily routines, making it easier to implement. Participant 6 shares, "It started part way through the year. Maybe if I started it in September or something like that, then I would've been able to do it on a more regular basis." Participant 4 expands on this idea:

I see the benefit more at the beginning of the year than now. So in the future, I would do it more. I would start out stronger at the beginning of the year, and would do it almost not very much now. Maybe reflect on it every once in a while. (Participant 4)

\subsubsection{Training}

Some of the teachers thought they would be better prepared to implement the MindMasters 2 resource if they had previously received training instead of the SSPs:

I don't know if they would offer any training on it for teachers to make better use of it. I don't know if I'm doing everything I can with it or not... I think that more teachers would be using it if they got the tool themselves... you know, if you do it, you retain it, but if it comes at you from somebody else, it's another thing. (Participant 1)

I'm sure I probably wasn't using it to the max that I probably could have. Having the training might've been able to help when using it at an appropriate time, or I probably could've used it better. (Participant 3)

\subsubsection{Variety in Activities}

Some teachers noted that for some of the activities, children were getting bored after a while. Therefore, they suggested introducing more variety in specific activities that could get repetitive. For example, participant 5 provides specific activities that could have more diversity:

If I had a request, like the clapping one [activity], the Good Little Listener and things like that, it was great, but once you've done it a couple times [they got bored]. Maybe it's the age of them, but it would have been nice if there was more. (Participant 5)

\subsection{Future Use of Resource}

Moving forward, when teachers were asked if they planned on continuing to use MindMasters 2 in the future, all of 
the teachers stated that they would. Some, like participant 4, even said they were willing to introduce the resource to other classrooms, "Yeah, I think so. And even in future years, I think that I would like to do it... I have a two/three [classroom] next year, so I definitely intend to use it with them." Participant 6 also had the same idea, "Yeah, I plan on using it with my other class as well. They're excited, because I said once the grades two and three were done, I would do it with them, so they're pretty excited."

\section{Discussion}

The goal of this study was to explore grade 3 teachers' perspectives on the efficacy and acceptability of MindMasters 2. The results from this study indicate that most teachers were able to implement each of the 11 activities at least 3 times over 3 months, despite fluctuations due to noted challenges. Three main challenges were reported when implementing MindMasters 2: time, student buy-in, and scheduling conflicts. Time was often cited by teachers as a barrier, and is reported in other school-based programs (i.e. Fixsen, Naoom, Blasé, Friedman, \& Wallace, 2005; Langley, Nadeem, Kataoka, Stein, \& Jaycox, 2010). Fortunately, activities found within the MindMasters 2 resource are relatively short, ranging from 5 to 15 minutes in length. Therefore, despite reporting a lack of time, teachers were still able to use the activities in an effective manner, overcoming this perceived challenge in order to meet the required level of exposure.

Some teachers observed that at the beginning of implementation, children would sometimes not take part in the activities, for reasons such as self-consciousness, the desire to be socially accepted, and silliness. However, this challenge seemed to diminish over time, as those children who were not buying into the program at first realized that it was safe and socially acceptable to join in. Such changes in attitude seemed to create a shift in the classroom "climate", where accepting one's emotions and being focused in the present moment was perceived as acceptable actions to engage in. This finding illustrates the importance of ongoing exposure, and urges teachers to remain patient and promote inclusion when doing activities.

Most teachers also felt that scheduling MindMasters 2 around SSP's availability made implementation more difficult. From the teachers' perspective, implementation would have been facilitated if they had received training beforehand. This is reinforced in CASEL's (2012) guide to effective social and emotional programming, where a main criterion for success is opportunity for training. For this study, school board staff did not feel there was enough time to train teachers first. They decided that since SSPs had received training several months before, they could introduce each activity once, allowing the classroom teacher to observe before using the activities independently. In the future, providing training to teachers could prove helpful.

Teachers reported that they used MindMasters 2 at various times during the day. However, it was consistently used during times when kids were transitioning from one school activity to another. In fact, some teachers even recommended that other teachers use MindMasters 2 in such a way to reduce transition time and increase focus and instruction time. This is an important finding, as MindMasters 2's facilitating role in transitions, in combination with its primary teaching role, makes it an appealing resource for schools.

Interestingly, all teachers used the resource as part of a routine. Teachers had mixed views on whether the program would work if used sporadically. From this study, it's unclear whether the way the resource is implemented plays a role in its effectiveness in a classroom setting. Previous research shows that other school- based social-emotional programs are consistently integrated into routines (i.e. Frey, Nolen, Edstrom, \& Hirschstein, 2005; Jones, Brown, Hoglund, \& Aber, 2010; Webster-Stratton, Reid, \& Stoolmiller, 2008). Therefore, implementation of MindMasters 2 may be more effective if used on a regular basis. Further research is needed to determine whether or not this is the case.

For the most part, teachers used the website as the main source for delivering MindMasters 2, as they found it well organized and easy to access. Surprisingly, they seldom used the software application and guidebook. Reasons given for this were a lack of time, lack of technological availability, and inconvenience. This is an important point, as previous research on web-based interventions for schools has also shown favorable outcomes (i.e. Lochman et al., 2017, Savage et al., 2010). Moving forward, program administrators may wish to evaluate the relevance of the less used formats, and consider investing more resources to the further development of the website.

Of great interest to this study were teachers' observations of changes that occurred in children after taking part in MindMasters 2 activities. Four main areas were discussed. On a classroom level, teachers felt that noise level and ease of instruction improved after using a MindMasters 2 activity. They noted this particularly during transition time. Some teachers observed that individual children were better able to regulate their emotions and focus on the task at hand. Teachers provided a few examples of children interacting with their peers in a positive way. These observations provide insight into the efficacy of MindMasters 2, and provide some anecdotal evidence to support 
the use of MindMasters 2 in schools to promote social and emotional skill development.

In regards to the acceptability of the resource, teachers reported that MindMasters 2 was easy to use, activities were short and simple, and students enjoyed them. Teachers also found MindMasters 2 quite applicable to real life situations. Most said they talked about situations where students could use the activities they learned in class. Some teachers also observed or heard about children using these activities outside the classroom, such as when they were feeling negative emotions, having trouble sleeping, or dealing with conflict. These results are similar to those observed in some positive youth development interventions, where the transfer of learned skills into real life situations is a main objective for success (Ciocanel, Power, Eriksen, \& Gillings, 2017). These examples of self-regulation may in turn prove to be relevant to promoting resilience and the development of effective coping skills (Zimmerman, 2013).

Teachers were able to provide various suggestions for improving the MindMasters 2 resource and the implementation process. One teacher suggested adding a parent section to the resource, so that students would be able to use it at home as well. This idea may further stimulate the use of the learned coping skills in other environmental contexts, and should be strongly considered. A few teachers also mentioned that more variety in certain activities was needed, as students began to lose interest with repeated activities. Several teachers noted that implementation would have been easier if they had started using the program in September. As noted earlier, some teachers suggested that it would be beneficial to receive MindMasters 2 training in advance of the beginning of the year, as opposed to relying on a third party for resource implementation. Taken together, the suggestions provided by teachers are important considerations to keep in mind in future implementation endeavors.

Overall, all teachers found the resource acceptable to use in a classroom setting, and were planning on using it in the future as a method of achieving curriculum criteria, as well as a resource to manage their classrooms during transition periods. Teachers also supported broader uptake of the resource, and felt every child could benefit from exposure to MindMasters 2.

\subsection{Implications}

Qualitative data from this study reveal that MindMasters 2 may be a valuable resource to teachers, and can be used to promote the development of social and emotional skills, focus in the classroom, positive peer relationships, and improved transitional periods in classrooms. This acceptance and endorsement is critical for broad uptake and sustainability in school systems. Another implication is that the feedback and suggestions provided by teachers through this evaluation subsequently provides program developers with tangible improvements that if implemented, have the potential to facilitate and enhance MindMasters 2's role in future classrooms. Lastly, implementation and evaluation of MindMasters 2 in this study may have provided a number of children and teachers with the knowledge and resources needed to address the positive living criteria in the provincial curriculum, positively impacting children's and teachers' quality of life in and out of the school environment.

\subsection{Limitations and Future Directions}

Although this study provided valuable information, it did have limitations. First, a small sample size of six teachers was recruited to participate in the interviews. With such a small number from a specific geographic location, we are unable to generalize our findings to the entire teacher population, as we are uncertain whether other teachers would have had different experiences with the resource. Future research should aim to recruit a larger sample of teachers to attain a better representation of the population.

Second, implementation of the program started halfway through the school year, and was only run for three months. Perhaps different results would have been observed if teachers had been able to use the resource from the beginning of the school year, as suggested by some teachers. This should be taken into consideration for future evaluations of MindMasters 2.

Lastly, coding of the interviews and identification of themes were done by only the principal investigator. Although peer-review briefing was conducted as a trustworthiness procedure, future studies should aim to have multiple coders for the analysis portion, so that disagreements between identified themes can be discussed, refined, and resolved collaboratively.

\subsection{Conclusion}

The results from this study demonstrate that according to some teachers, MindMasters 2 is a valuable resource to use in classroom settings, and may play a role in improving children's social and emotional skills, which may in turn foster resilience. MindMasters 2 could prove useful in helping schools meet specific health-related curriculum objectives for students 4-9 years of age. Ongoing evaluation will ensure that MindMasters 2 resources are relevant, 
effective, and implemented successfully.

\section{Acknowledgements}

The author would like to thank Dr. Terry Orlick and Ms. Corrine Langill for their support and assistance in this research project.

\section{References}

Bond, L., Butler, H., Thomas, L., Carlin, J., Glover, S., Bowes, G., et al. (2007). Social and school connectedness in early secondary school as predictors of late teenage substance use, mental health, and academic outcomes. Journal of Adolescent Health, 40(4), 357.e9-357.e18. http://dx.doi.org/10.1016/j.jadohealth.2006.10.013

Braun, V., \& Clarke, V. (2006). Using thematic analysis in psychology. Qualitative Research in Psychology, 3(2), 77-101. http://dx.doi.org/10.1191/1478088706qp063oa

Brooks, R., \& Goldstein, S. (2001). Raising resilient children: Fostering strength, hope and optimism in our children. New York, NY: McGraw-Hill.

Brown, K. W., \& Ryan, R. M. (2003). The benefits of being present: Mindfulness and its role in psychological $\begin{array}{llllll}\text { well-being. Journal of Personality and Social Psychology, } & 84(4), & 822 .\end{array}$ http://dx.doi.org/10.1037/0022-3514.84.4.822

Carthy Foundation \& Max Bell Foundation. (2013). Issue brief: Social and emotional learning in Canada. http://www.maxbell.org/sites/default/files/SELIssueBrief.pdf. Accessed 12 December 2015.

Children's Hospital of Eastern Ontario. (2016). MindMasters 2. http://www.cyhneo.ca/\#!mindmasters-2/dha2r. Accessed 22 September 2015.

Collaborative for Academic, Social, and Emotional Learning [CASEL]. (2012). 2013 CASEL guide: Effective social and emotional learning programs - Preschool and elementary school edition. Chicago, IL: Author.

Durlak, J. A., Weissberg, R. P., Dymnicki, A. B., Taylor, R. D., \& Schellinger, K. B. (2011). The impact of enhancing students' social and emotional learning: A meta-analysis of school- based universal interventions. Child Development, 82, 405-432. http://dx.doi.org/10.1111/j.1467-8624.2010.01564.x

Fixsen, D. L., Naoom, S. F., Blasé, K. A., Friedman, R. M., \& Wallace, F. (2005). Implementation research: A synthesis of the literature. Tampa, FL: University of South Florida, Louis de la Parte Florida Mental Health Institute, The National Implementation Research Network.

Frey, K. S., Nolen, S. B., Edstrom, L. V. S., \& Hirschstein, M. K. (2005). Effects of a school-based social-emotional competence program: Linking children's goals, attributions, and behavior. Applied Developmental Psychology, 26, 171-200. http://dx.doi.org/10.1016/j.appdev.2004.12.002

Fylan, F. (2011). Semi-structured interviewing. In J. Miles \& P. Gilbert (Eds.), A handbook of research methods for clinical and health psychology (pp. 65-78). Oxford, NY: Oxford University Press.

Garmezy, N. (1985). Stress-resistant children: The search for protective factors. In J. E. Stevenson (Ed.), Recent research in developmental psychopathology: Journal of Child Psychology and Psychiatry Book Supplement \#4 (pp. 213-233). Oxford: Pergamon.

Goldstein, S., \& Brooks, R. B. (2012). Handbook of resilience in children (2nd ed.). New York; London: Springer.

Greenberg, M. T., Weissberg, R. P., O’Brien, M. U., Zins, J. E., Fredericks, L., Resnik, H., et al. (2003). Enhancing school-based prevention and youth development through coordinated social, emotional, and academic learning. American Psychologist, 58(7), 466-474.

Harnett, P. H., \& Dawe, S. (2012). The contribution of mindfulness - based therapies for children and families and proposed conceptual integration. Child and Adolescent Mental Health, 17(4), 195-208. http://dx.doi.org/ 10.1111/j.1475-3588.2011.00643.x

Hodder, R. K., Freund, M., Wolfenden, L., Bowman, J., Nepal, S., Dray, J., et al. (2017). Systematic review of universal school-based 'resilience' interventions targeting adolescent tobacco, alcohol or illicit substance use: A meta-analysis. Preventative Medicine, 100, 248-268. http://dx.doi.org/ 10.1016/j.ypmed.2017.04.003

Horn, T. S. (2008). Advances in sport psychology. Champaign, IL: Human Kinetics.

Jones, S. M., Brown, J. L., Hoglund, W., \& Aber, J. L. (2010). A school-randomized clinical trial of an integrated social-emotional learning and literacy intervention: Impacts after one school year. Journal of Consulting and Clinical Psychology, 78(6), 829-842. http://dx.doi.org/ 10.1037/a0021383 
Langley, A., Nadeem, E., Kataoka, S., Stein, B., \& Jaycox, L. (2010). Evidence-based mental health programs in schools: Barriers and facilitators of successful implementation. School Mental Health, 2(3), 105-113. http://dx.doi.org/ 10.1007/s12310-010-9038-1

Lochman, J. E., Boxmeyer, C. L., Jones, S., Qu, L., Ewoldsen, D., \& Nelson, W. M. (2017). Testing the feasibility of a briefer school-based preventative intervention with aggressive children: A hybrid intervention with face-to-face and internet components. Journal of School Psychology, 62, 33-50. http://dx.doi.org/ 10.1016/j.jsp.2017.03.010

Masten, A. S. (2007). Resilience in developing systems: Progress and promise as the fourth wave rises. Development and Psychopathology, 19, 921-930. http://dx.doi.org/ 10.1017/S0954579407000442

Mental Health Commission of Canada. (2012). Changing directions, changing lives: The mental health strategy for Canada. Calgary, AB: Author.

Ontario Ministry of Education. (2015). The Ontario curriculum grades 1 - 8: Health and physical education. http://www.edu.gov.on.ca/eng/curriculum/elementary/health1to8.pdf. Accessed 8 December 2015.

Payton, J. W., Wardlaw, D. M., Graczyk, P. A., Bloodworth, M. R., Tompsett, C. J., \& Weissberg, R. P. (2000). Social and emotional learning: A framework for promoting mental health and reducing risk behavior in children and youth. Journal of School Health, 70(5), 179-185. http://dx.doi.org/ 10.1111/j.1746-1561.2000.tb06468.x

QSR International Pty Ltd. (2015). NVivo qualitative data analysis software: Version 11.

Rutter, M. (1987). Psychosocial resilience and protective mechanisms. New York, NY: Irvington.

Savage, R. S., Erten, O., Abrami, P., Hipps, G., Comaskey, E., \& van Lierop, D. (2010). ABRACADABRA in the hands of teachers: The effectiveness of a web-based literacy intervention in grade 1 language arts programs. Computers \& Education, 55(2), 911- 922. https://doi.org/10.1016/j.compedu.2010.04.002

Stronge, J. H. (2010). Effective teachers = student achievement: What the research says. Larchmont, NY: Eye on Education.

Tang, Y., Posner, M. I., \& Rothbart, M. K. (2014). Meditation improves self-regulation over the life span. Annals of the New York Academy of Sciences, 1307, 104-111. http://dx.doi.org/ 10.1111/nyas. 12227

van Teijlingen, E., \& Hundley, V. (2002). The importance of pilot studies. Nursing Standard, 16(40), 33-36. http://dx.doi.org/ 10.7748/ns2002.06.16.40.33.c3214

Webster-Stratton, C., Reid, M. J., \& Stoolmiller, M. (2008). Preventing conduct problems and improving school readiness: Evaluation of the Incredible Years Teacher and Child Training Programs in high-risk schools. Journal of Child Psychology and Psychiatry, 49, 471-488. http://dx.doi.org/ 10.1111/j.1469-7610.2007.01861.x

Zimmerman, M. A. (2013). Resiliency theory: A strengths-based approach to research and practice for adolescent health. Health Education \& Behaviour, 40(4), 381-383. http://dx.doi.org/ 10.1177/1090198113493782

Zins, J. E. (Ed.). (2004). Building academic success on social and emotional learning: What does the research say? New York, NY: Teachers College Press.

\section{Copyrights}

Copyright for this article is retained by the author(s), with first publication rights granted to the journal.

This is an open-access article distributed under the terms and conditions of the Creative Commons Attribution license (http://creativecommons.org/licenses/by/4.0/). 